\title{
RESEARCH ON THE EVOLUTION OF SENSORY AND PHYSICO-CHEMICAL CHARACTERISTICS OF BUTTER WITH THE ADDITION OF MINT AND PEPPERMINT
}

\author{
Mihaela Adriana, Tița ${ }^{1}$, Butoi Laurenţiu \\ 1"Lucian Blaga" University of Sibiu, mihaela.tita@ulbsibiu.ro \\ 2’"'Terezianum" Technological High School of Food Industry, butoi.laurentiu@yahoo.com
}

\begin{abstract}
This research aims to develop a new technology for the enrichment of butter with mint oil and mint oil which will improve its nutritional quality and may become one of the consumer's preferences. Also mint has an aromatic, characteristic odor with stinking, with a pungent, refreshing taste,, and mint oil contains numerous minerals and nutrients including iron, manganese, magnesium, calcium, folic acid, potassium and copper, vitamin A and $\mathrm{C}$. The butter obtained with the addition of mint and mint oil has been subjected to a comparative test with a sample of blank butter and analyzed for a period of 30 days, analyzing changes in sensory and physico-chemical.
\end{abstract}

KEY WORDS: new technology, nutritional, functional properties

\section{INTRODUCTION}

Interest by consumers in diet and health seems to drive butter production toward a niche market that appreciates the high quality, unique flavor, and natural image of butter. Butter production is likely to follow a similar trend as with other products within the dairy industry (liquid milk, cheese, yogurt, ice cream), with improvements in functional properties, both physical and nutritional. If maintaining a "natural" image for butter is critical, it would follow that such changes would be achieved through the dairy cow, for ex-ample, by diet or genetics. Naturally spreadable butters have been mentioned previously but "healthier" butters enhanced with omega-3 PUFA or enriched with CLA (for many potential and varied health benefits) have also been achieved through modification of the cow's diet. A growing sector within the butter industry is also the production of butter-based ingredients for the food manufacturing industry such as ready-mixed butter-based mixtures of butter, flour, sugar, or vegetable oil. Butter will continue as a premium product but development of nutritionally enriched high-milk fat dairy spreads with improved omega-6:omega-3 ratios will provide stern competition. [1] In modern butter processing, it is intended to obtain various types of butter with different additions, which are of particular interest in the research area. There is research using plant or apiculture products, for example: this study was to investigate the effect of incorporating tomato processing by-products (TPB) extract on oxidation, chemical properties and fatty acid profile of traditional Tunisian butter (TTB) during refrigerated storage [2], the antioxidant effects of extracts of propolis.[3] or essential oil of $\mathrm{S}$. cilicica could be used as both natural antioxidant and aroma agent in butter.[4] In a study of carrot powder enriched with butter it has been shown to improve the organoleptic and consistency properties by increasing the toughness and heat resistance.[5] Another study, namely adding cinnamon butter containing bioactive ingredients such as antioxidants, polyphenols and flavonoids extended shelf life of butter due to its antioxidant activity.[6]

In this study was used Mentha. Mentha (mint) was used as medicinal herb in ancient times, but menthol crystals are still used in different pharmaceutical products and cosmetics as antiseptic, stimulant and inhibitor.[7] Mint oil and its constituents and derivatives are also used as flavoring agents throughout the world in food, pharmaceutical, perfumery, and flavoring industry [8]

\section{MATERIALS AND METHODS}

The research has been performed in the milk technology laboratory, and the study used sweet cream from a private dairy factory, which was analyzed for acidity and $\mathrm{pH}$. It was heated to a temperature of $22^{\circ} \mathrm{C}$ and seeded with a Starter culture of mesophilic lactic acid bacteria formed only from Streptococcus, being submit operation biochemical maturation in the oven (at $22^{\circ} \mathrm{C}$ ) until the acidity of $60^{\circ} \mathrm{T}$. The biochemically matured sour cream was cooled to $6^{\circ} \mathrm{C}$ and left to physical maturation for 10 hours. With the help a mixer, has been submit to a beating operation and resulted the butter. The amount of butter obtained was divided into 5 equal parts, so one part was the control sample, in three parts different amounts of peppermint oil were put, and in the last part was made fresh mint leaves.

In making this study, the methods of analysis used are [9]:

1. Sensory analysis was performed to assess the sensory characteristics by the scoring method.

2. Determination of acidity, by titration with $0,1 \mathrm{~N}$ sodium hydroxide solution in the presence of phenolphthalein as an indicator, the result being expressed in degrees of acidity; according to STAS 6353-75.

3. Determination of the acidity index is the amount of potassium or sodium hydroxide required to neutralize free fatty acids contained in one gram of fat, expressed in milligrams of reagent/gram of fat, according to STAS 9952/2-82.

4. Determination of saponification index: The quantity of potassium hydroxide required to saponification one gram of fat, expressed in $\mathrm{mg} \mathrm{KOH} / \mathrm{g}$ of fat.

5. Determination of water activities with the Novasina apparatus. 
6.Determination of freshness by the Kreiss reaction, is achieved by treating the butter sample

in acid medium with floroglucin. The appearance of a red color indicates the presence of the epihydrin aldehyde resulting from the first stage of butter degradation according to STAS 635074.

\section{RESULTS AND DISCUSSION}

The following butter samples were taken, with the addition of different quantities of mint and mint oil, symbolized as follows:

$>$ PM- The control sample

$>$ Sample 1 (U10M): 150 grams of butter, to which $10 \mathrm{ml}$ of mint oil has been added;

$>$ Sample 2 (U20M): 150 grams of butter, to which $20 \mathrm{ml}$ of mint oil has been added;

> Sample 3 (U30M): 150 grams of butter, to which $30 \mathrm{ml}$ of mint oil has been added;

$>$ Sample 4 (U1MT): 150 grams of butter to which 1 gram of mint is added.

The samples of butter with added samples were analyzed for a period of 30 days.

The results obtained are presented as follows:

a). Sensory analysis

- The results obtained for sensory characteristic - Taste are presented in the following figure:

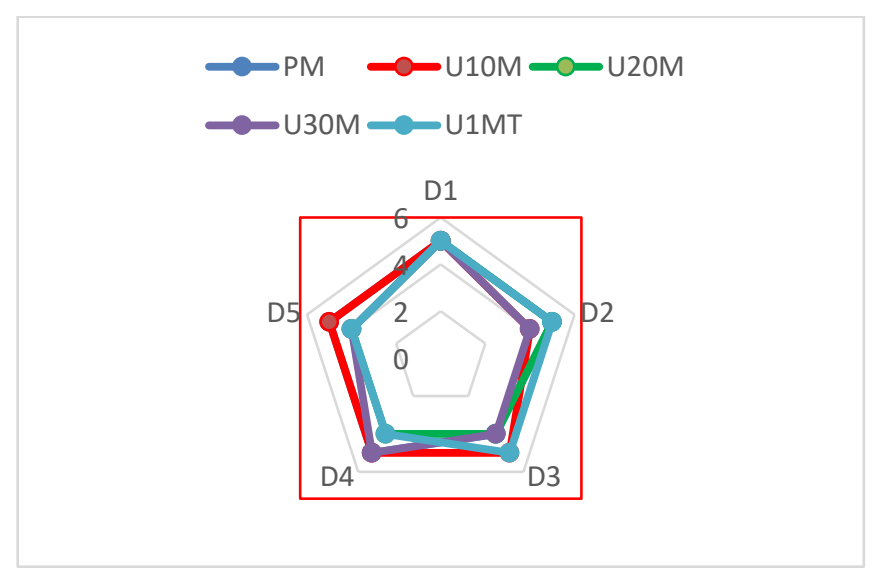

Figure 1. Sensory characteristic - Taste

From the results obtained it is noted that the butter with added $10 \mathrm{ml}$ of mint oil has obtained the greatest flavor score relative to the other peppermint oil samples.

- The results obtained for the sensory characteristic Smell are presented in figure no.2:
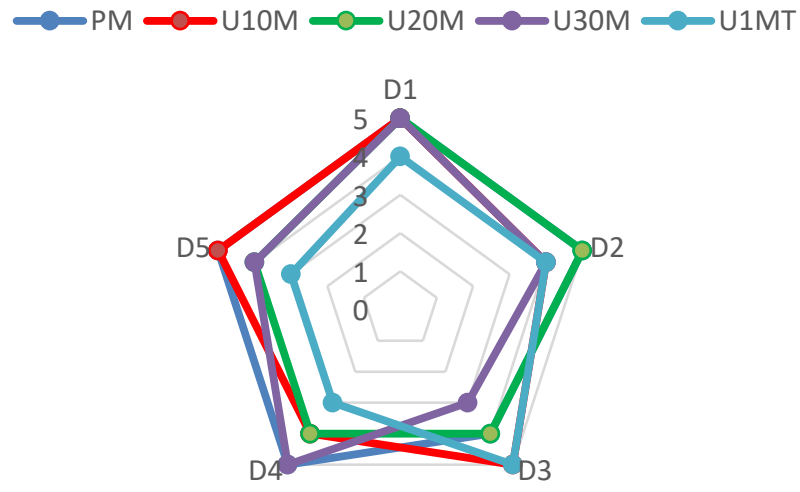

Figure 2. Sensory characteristics - Smell

From the obtained results it is observed that also with the sensory characteristic for the smell, the butter with the addition of dried mint obtained a lower score from the tasters compared to the other samples with the addition of peppermint oil, even compared to the butter without any addition.

- The results obtained for the sensory characteristic Consistency are presented in the following figure:

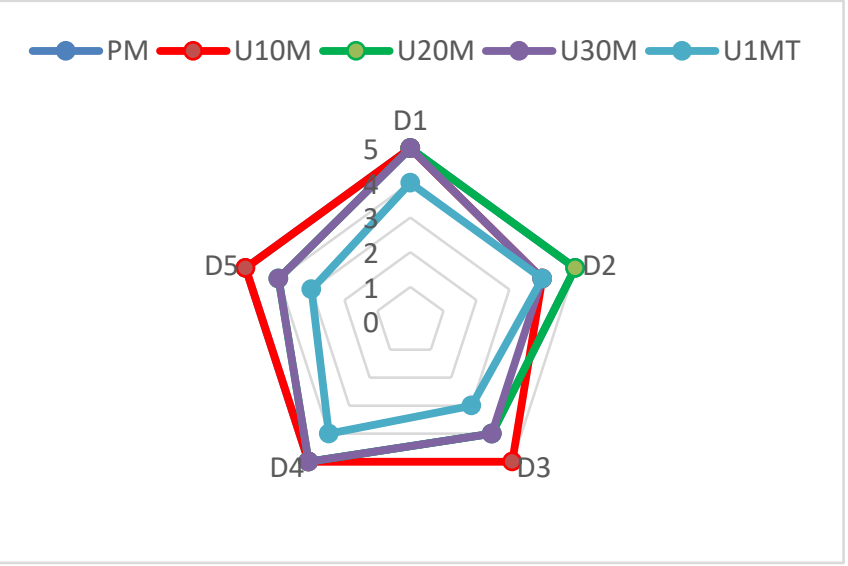

Figure 3. Sensory characteristic - Consistency

Also, from the graphic representation it is observed that the butter with the addition of dried mint has the lowest score for the sensory characteristic consistency, and the butter with the addition of $10 \mathrm{ml}$ and $20 \mathrm{ml}$ of peppermint oil, received the highest score.

- The results obtained for the sensory characteristic Color are presented in figures no.4:
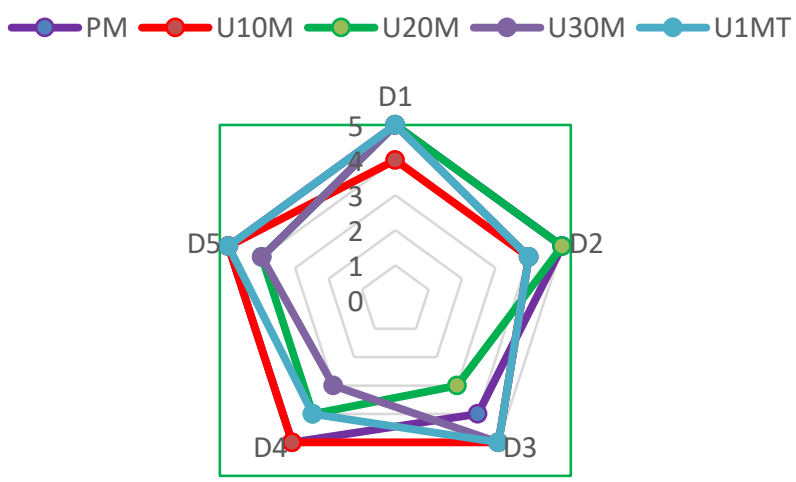

Figure 4. Sensory characteristic - Color 
From the presented results the butter with the addition of $10 \mathrm{ml}$ of peppermint oil obtained the highest score compared to the other 3 samples of butter with the addition of vegetable product, and the butter as such obtained the highest score.

- The results obtained for the sensory characteristic appearance in section are presented in the following figure no.5:

It is observed that the score given for the sensory characteristic - aspect in section, of the control sample is the highest compared to the other samples and the sample with dried mint obtained the lowest score because at the time of cutting in section there were small pieces of mint that came out from the cut piece of butter.
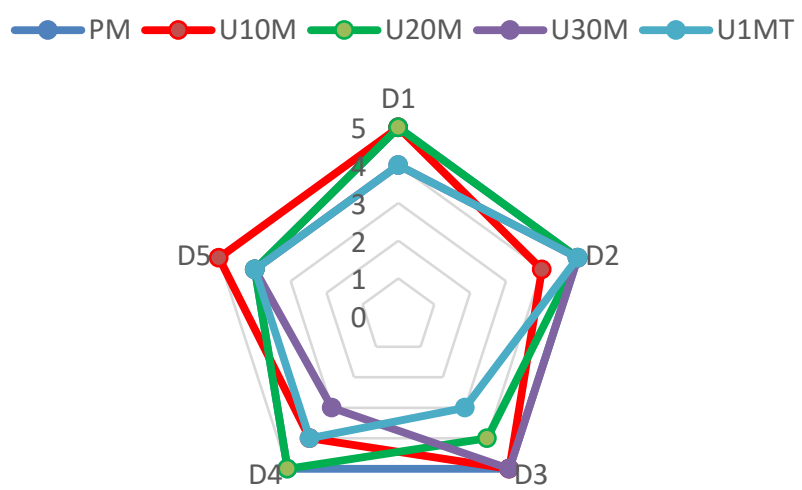

Figure 5. Sensory characteristic - Appearance in section

\section{b). Determination of butter acidity}

The results obtained from the determination of the acidity of the analyzed samples are presented in the following figure:

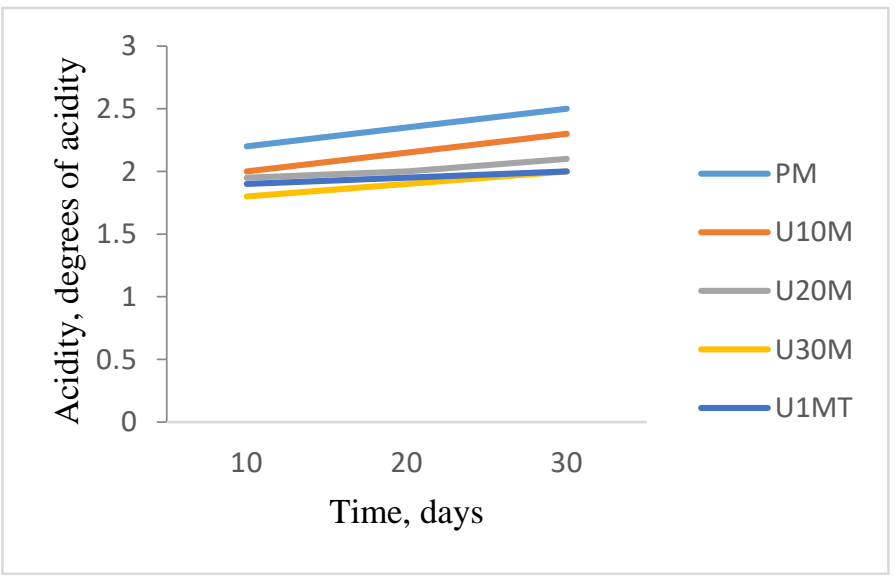

Figure 6. Evolution of acidity of analyzed butter samples

It is observed from the results presented that the control sample has the highest acidity, but which falls within the quality standards. The other samples of peppermint oil show small increases in acidity due to the content of specific compounds in peppermint oil which did not allow too high an increase in acidity. The U1MT sample has the lowest acidity because the mint used comes with a dry matter content so acidification processes are slower.

\section{c). Determination of acidity index}

The results obtained from the determinations of the acidity index of the analyzed samples are presented in the following figure no.7.

From the obtained results it is observed that the acidity index increases over the analyzed period for all butter samples analyzed so that it gives us information about the shelf life of butter which is closely dependent on some sensory properties such as taste and smell, which changes over time. which are due to the transformations undergone by fat, mainly due to the presence of free fatty acids.

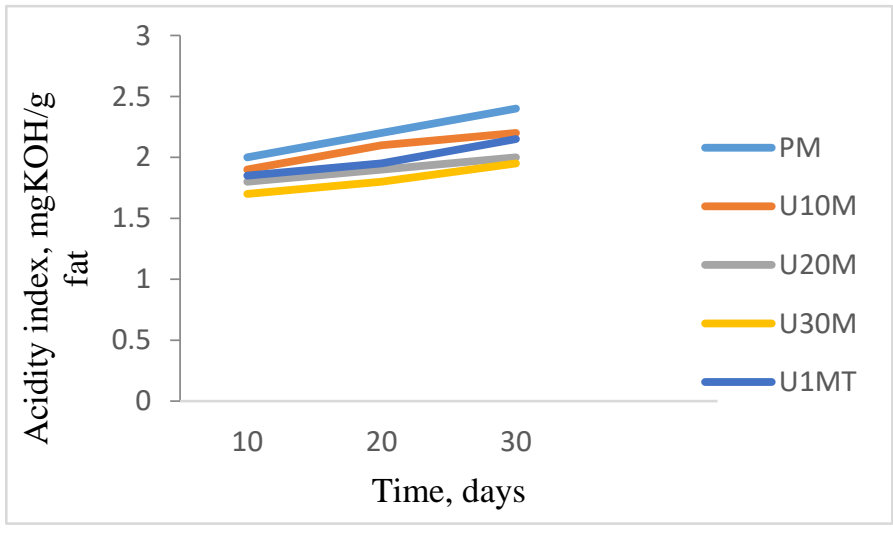

Figure7.Evolution of acidity index of analyzed butter samples

\section{d). Determination of the saponification index}

The results obtained following the determinations of the saponification indices of the analyzed samples are presented in figure no.8

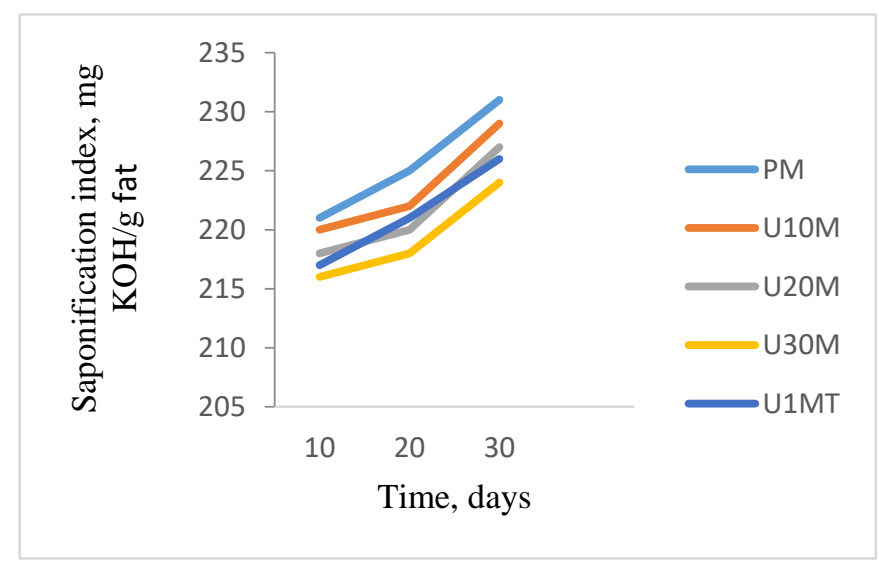

Figure 8. Evolution of saponification index of analyzed butter samples

The saponification index, for all analyzed samples shows an increase throughout the analyzed period and indicates that in the analyzed samples there is a higher content of lower fatty acids with lower molecular weight. The results obtained are within the standards in force, where the saponification index varies between 219 - 235 .

e). Determination of water activity 
The results obtained from the determinations of the water acidity of the analyzed samples are presented in the following figure no.7.

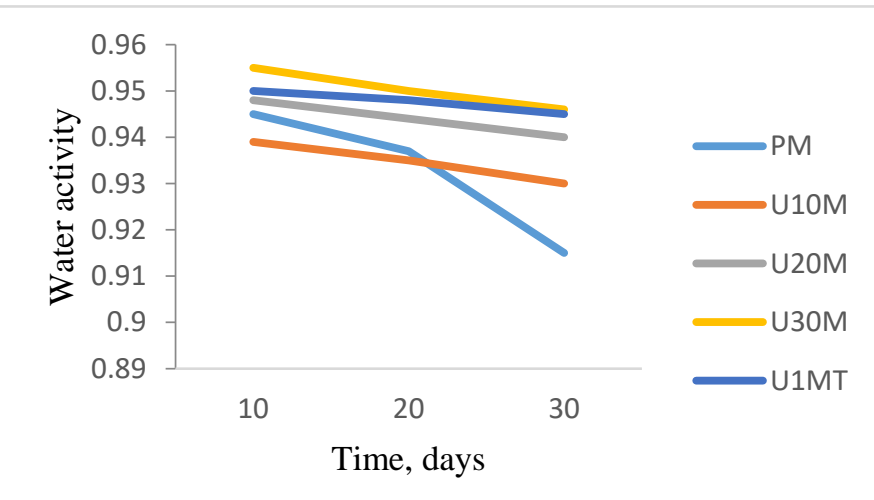

Figure 9. Evolution of water activity index of analyzed butter samples

The activity of water in the case of butter is the result of physical and chemical phenomena, so that it is not stable during the storage of butter samples, decreasing until it reaches a balance between the surface of the product and the surrounding atmosphere. The graph shows that the water activity decreases slowly for all the analyzed samples.

f. Determination of the freshness of the butter by the Kreiss method

The results obtained are presented in the following table:

Tabel 1. The freshness of the analyzed butter samples

\begin{tabular}{|l|l|l|}
\hline $\begin{array}{l}\text { Nr. } \\
\text { Crt }\end{array}$ & Sample & $\begin{array}{l}\text { The degree of freshness depending on } \\
\text { the color }\end{array}$ \\
\hline 1 & PM & White - yellow - fresh butter \\
\hline 2 & U10M & White - yellow - fresh butter \\
\hline 3 & U20M & White - yellow - fresh butter \\
\hline 4 & U30M & White - yellow - fresh butter \\
\hline 5 & U1MT & $\begin{array}{l}\text { White - yellowish with a slight tinge } \\
\text { due to the content of mint leaves. - } \\
\text { Fresh butter }\end{array}$ \\
\hline
\end{tabular}

From the results obtained that during the 30 days, the butter samples have another degree of freshness, which should be noted that the quality of the raw material is of particular importance.

\section{CONCLUSIONS}

Based on the results, it can be concluded that butter with the addition of peppermint oil and mint has good physicochemical properties during the analyzed period. Therefore, this research clearly shows that peppermint oil and mint can be successfully incorporated as an ingredient to obtain a innovative butter assortment.

\section{REFERENCES}

1.Dairy Processing \&Quality, Assurance, Editor Ramesh C.Chandan, JohnWiley\&Sons, Inc. ISBN 978-0-813-82756-8, p.253, (2008)
2. Yousra Abid, Samia Azabou, Mourad Jridi, Ibtihel Khemakhem, Mohamed Bouaziz, Hamadi Attia, Storage stability of traditional Tunisian butter enriched with antioxidant extract from tomato processing by-products, Food Chemistry 233, 476-482, (2017)

3. Özcan, M., \& Ayar, A., Effect of propolis extracts on butter stability.Journal of Food Quality, 26(1), 65-73, (2003)

4. Ozkan, G., Simsek, B., \& Kuleasan, H., Antioxidant activities of Satureja cilicica essential oil in butter and in vitro.Journal of Food Engineering, 79(4),1391-1396, (2007)

5. Gulcan Ozkan, Bedia Simsek, Hakan Kuleasan, Antioxidant activities of Satureja cilicica essential oil in butter and in vitro, Journal of Food Engineering, 79 p.1391-1396, (2007)

6. Rashevska, T.O., Vasheka, O.M., The technology of butters' enriching with carrots' powder, Procedia Food Science, nr.1, pag.1404-1049, (2011)

7. M. Akram, M. Uzair, Nadia Shamshad Malik, Arshad Mahmood, Naila Sarwer, Asadullah Madni and H. M. Asif, Mentha arvensisLinn.: A review article, Journal of Medicinal Plants Research Vol. 5(18), pp. 4499-4503, (2011)

8. Balakrishnan A. Therapeutic uses of peppermint-a review. Journal of Pharmaceutical Sciences and Research. 7(7): 474476, (2015)

9.Tița Mihaela Adriana, "Manual de analiză și controlul calității în industria laptelui", Editura Universității "Lucian Blaga" din Sibiu, (2005) 